\title{
ALGUNAS ESPECIES ARBÓREAS Y ARBUSTIVAS PRESENTES EN EL CORÁN
}

\section{Julia María Carabaza Bravo}

Elegir un tema de trabajo para el homenaje de mi querida compañera Eugenia ha sido tarea fácil: aún guardo las notas que, durante algún tiempo, me proporcionó sobre las plantas mencionadas en el libro sagrado del Islam, sabedora de mi interés por la botánica y la agricultura árabes. Como agradecida respuesta a sus continuas atenciones, y segura de que todo estudio relacionado con el Corán le interesa y satisface, presento en estas breves páginas algunas consideraciones sobre diversos árboles y arbustos que se citan en dicho libro, dejando atrás otras especies vegetales -especias, legumbres, hortalizas, cereales...-de menor presencia en él. Concretamente, dado el espacio de que dispongo, voy a detenerme en las tres plantas más citadas en el Corán: la palmera, la vid y el olivo, a las que acompañarán el resto de las especies en posibles trabajos futuros.

Indudablemente, no soy la primera en abordar este tema ${ }^{1}$, pero son tan ricos y variados los comentarios que pueden hacerse sobre él que, creo, siempre resulta interesante volver nuestros ojos una vez más al libro sagrado islámico y a otras obras relacionadas con la tradición profética. En este sentido, y puesto que ya se han establecido las identificaciones botánicas de las especies vegetales presentes en el Corán, sus lugares de origen, tipos de cultivo, usos alimentarios y terapéuticos actuales, etc., quiero apuntar algunos datos sobre el contexto religioso en que se inscriben las tres plantas mencionadas tanto en este libro como en los hadices, y las aplicaciones médicas de que son objeto en la llamada "medicina del Profeta" (tibb al-nabĩ), de tanta importancia en el mundo islámico pese a la presencia de la que se ha denominado "medicina racional", basada en los postulados científicos griegos principalmente ${ }^{2}$. Del mismo modo, añado otros comentarios sobre estas tres especies hallados en fuentes agronómicas, en concreto aquellos que conectan de cerca con la tradición profética. Para llevar a cabo lo dicho, sigo el orden del número de citas -en grado descendente- que posee cada una de ellas en el Corán, obra que siempre tomo como punto de partida.

La palmera (Farooqi 1989: 22-33; Manșūr 1994: 51-65) es, con diferencia, el árbol más veces citado en el libro sagrado del Islam [como najl, najla o najil se nombra en veinte

\footnotetext{
${ }^{1}$ Véanse, entre otros, los siguientes trabajos básicos: M.I.H. Farooqi, Plants of the Quran (Aminabad 1989); ${ }^{\mathrm{c} A .}$ Manșūr, al-Nabātāt fî̀ l-Qur'ān al-karīm ('Ammān 1994).

${ }^{2}$ Cfr. Ibn Habīb, Mujtașar fīl-tibb (Compendio de Medicina), introd., ed. y trad. C. Álvarez de Morales y F. Girón Irueste (Madrid 1992) 19-29. En la página 23 podemos leer como definición de este tipo de medicina: "El contenido de la Medicina del Profeta está estructurado a base de pequeños episodios en los que Muhammad, sus familiares o sus compañeros, en su relación diaria con los personajes que les frecuentan o, en ocasiones, gente del pueblo, aconsejan o imponen acciones terapéuticas, de acuerdo con sus propios conocimientos, o los elementos que les sugieren los médicos de los que se encuentran rodeados, o a los que hacen llamar".
} 
ocasiones] y el que mayor repercusión tendrá, como veremos, en la medicina del Profeta. Prácticamente siempre aparece en pasajes coránicos de marcado carácter positivo, como árbol de abundante fruto propio de jardines espléndidos y del Paraíso, y que el favor divino ha concedido a la humanidad para su sustento:

"Él es Quien ha hecho bajar agua del cielo. Mediante ella hacemos brotar toda clase de plantas y follaje, del que sacamos granos arracimados. De las vainas de la palmera, racimos de dátiles al alcance..." (VI, 99). "La tierra la ha puesto al servicio de las criaturas. Hay en ella fruta y palmeras de fruto recubierto" (LV, 10-11) ${ }^{3}$.

En el mismo contexto positivo se encuentra este árbol en los hadices en los que el Profeta Muhammad insiste, repetidamente ${ }^{4}$, en la conveniencia de consumir dátiles para gozar de buena salud, y en la necesidad de tener siempre estos frutos en la casa por tratarse de un sustento básico, al tiempo que nos habla de cómo ha de hacerse su venta, cómo consumirlos, de la prohibición de obtener una bebida alcohólica partiendo tanto de ellos como de otros productos, algunos de sus usos medicinales, etc. ${ }^{5}$ :

"El Profeta, Dios lo bendiga y salve, dijo: no pasará hambre la gente de la casa en la que haya dátiles", o bien "Dijo el Profeta, Dios lo bendiga y salve: ' $\overline{\mathrm{A}}$ 'iša, pasará hambre la gente en cuya casa no haya dátiles, y lo repitió dos o tres veces" ${ }^{\prime \prime}$.

"El Profeta, Dios lo bendiga y salve, dijo: ya se ha establecido la prohibición de la bebida alcohólica que proviene de cinco cosas: las uvas, los dátiles, el trigo, la cebada y la miel..."; "c $\overline{\mathrm{A}}$ 'iša, que Dios tenga en su santa gloria, dijo: la familia del Profeta Muhammad sólo hace dos comidas al día y una de ellas siempre son dátiles"”.

\footnotetext{
${ }^{3}$ Véase, igualmente, El Corán, trad. J. Cortés (Madrid 1980), sura VI, aleya 141, sura XVI, aleyas 11 y 67, sura XVII, aleya 91, sura XXIII, aleya 19, sura XXXVI, aleyas 33-35, sura L, aleyas 9-11, y sura LXXX, aleyas 24-29 [de aquí en adelante tan sólo nombraremos el título de la obra sin cursiva, más los números de las azoras y aleyas correspondientes].

${ }^{4}$ Tan sólo en el Ṣaḥ̣̣h de al-Bujārī se nombra en ciento veinticinco ocasiones este fruto de la palmera.

5 En todos los ejemplos de hadices que voy a dar a lo largo del artículo excluyo la cadena de transmisores que anteceden a la información expuesta, y a veces no ofrezco el texto completo sino la parte que interesa a nuestro tema, con objeto de no alargar en exceso las citas.

${ }^{6}$ Saḥ̂h de Muslim, números 3811 y 3812, e igualmente Sunan de al-Dārimī números 1972 y 1971 en Mawsü $\bar{u}^{c}$ at alhadīt al-šarîf (El Cairo $1997^{2}$ ) CD-Rom, s.v. "tamr". Este término posee más de ochocientas entradas en el total de las obras que integran esta enciclopedia, mientras que el vocablo najl posee algo menos de la mitad.

7 Al-Bujārī, Șạ̣ịh, ed. M. 'A. Al-Quṭ y H. al-Bujārī (Beirut 1999³) IV, 1794 número 5588 y 2028 número 6455. Puede verse, igualmente, al-Nawawī, Riyāẹ al-sāaliḥ̂n min kalām sayyid al-mursalīn, s. ed. (Beirut 1998) 230 número 740 y 330-331 números 1236 y 1237, trad. M. Zorrilla: El jardín de los justos. La tradición oral del Islam, los hadices, recopilada en el siglo XIII (Gerona s. a.) 213 número 745 y 301 números 1243 y 1244.
} 
Incluso, en los hadices la palmera aparece como un árbol bendito al ser comparada con el propio creyente musulmán: "El Profeta, Dios lo bendiga y salve, dijo: de entre todos los árboles hay uno que es como el musulmán y es la palmera"8.

En las obras de medicina profética, los dátiles se cuentan entre los frutos más utilizados para remediar diversos males. De este modo, además de hablarse sobre sus variedades de mayor efecto terapéutico, se indican las siguientes acciones: previenen contra los cólicos y la humedad corporal; curten el estómago; aumentan el apetito sexual; si la mujer pone algunos en su vagina antes del coito, queda embarazada fácilmente; si se comen siete dátiles durante siete días, al salir el sol y en ayunas, se previene el vértigo; si se mezclan siete dátiles (de la variedad ${ }^{c} a \hat{y} w a$ ) con costo indio, cúrcuma y aceite de oliva y se administran, curan las enfermedades cardíacas; si se ingieren siete dátiles (de la variedad antes indicada) por la mañana, hasta el final del día no afectan a la persona ni hechizos ni venenos; o bien, si se comen siete dátiles (de la misma variedad) al acostarse, se matan las tenias ${ }^{9}$.

Igualmente, se expone que no hay alimento mejor para la recién parida que los dátiles frescos o, en su defecto, los dátiles secos mojados, en alusión directa a la azora de María como bien indican Ibn Habīb, al-Dahabī, al-Suyūțī y el persa al-Chaghayni. El primero nos dice: "Ello se debe a que cuando María parió, Dios se los dio como alimento. Y yo he oído decir que la palmera de María estaba llena de dátiles"10. Por el contrario, hay que evitar la ingestión de dátiles, o tomar muy poca cantidad de ellos y lentamente, en dos circunstancias: cuando se está convaleciente o bien se padece de oftalmía ${ }^{11}$.

En el Corán se hallan dos pasajes donde se compara a las personas con troncos de palmera $^{12} \mathrm{y}$, en los hadices, se cuenta que el tronco de la palmera en el que solía apoyarse el Profeta para predicar lloró cuando éste, en su lugar, se sentó en el minbar de la mezquita. Sus lamentos eran como el llanto de un niño, por lo que el Profeta tuvo que abrazarlo y consolarlo hasta que, ya satisfecho, calló ${ }^{13}$. En la misma línea, la Agricultura Nabatea también ofrece

\footnotetext{
${ }^{8}$ Al-Bujārī, Saḥịh IV, 1750 número 5448. En la obra de al-Suyūtīi, de carácter médico-profético, también se recoge esta tradición: C. Elgood, "Tibb-ul-Nabbi or Medicine of the Profet, being a translation of two works of the same name: I.- The Tibb-ul-Nabbi of al-Suyútí. II.- The Tibb-ul-Nabbi of Maḥmúd bin Mohamed al-Chaghhayni together with introduction, notes \& a glossary", Osiris, 14 (1962), 77 y 96.

${ }^{9}$ M. al-Dahabī, al-Tíbb al-nabawī, s. ed. (El Cairo 1961) 38-40; C. Elgood, "Tibb-ul-Nabbi”, 71-72, 74-76, 87, 9697 y 115; Ibn Habib, Mujtașar, 22 (ed.)/55 (trad.), 23/57 y 39-40/72. También se hallan algunos de estos remedios en la tradición profética de tema médico de la doctrina šíí duodecimana: Islamic Medical Wisdom. The Tibb alA'imma, ed. A. J. Newman, transl. B. Ispahany (Londres 1991) 78-79, 103 y 106.

${ }^{10}$ Ibn Habīb, Mujtașar, 39/71. Véase M. al-Dahabī, al-Ṭibb al-nabawī, 38-39; C. Elgood, "Tibb-ul-Nabbi”, 75 y 189. Cfr. Corán, XIX, 23-25.

11 M. al-Dahabī, al-Tibb al-nabawī, 40; C. Elgood, “Tibb-ul-Nabbi”, 127-128; Ibn Habīb, Mujtașar, 13/46-47 y $21 / 54$.

12 Corán, LIV, 20 y LXIX, 7.

13 Al-Nawawī, Riyāẹ al-șāliḥ̂̄n, 474 número 1829 y El Jardín de los justos, 423 número 1837.
} 
similitudes entre el hombre y esta palmácea, tanto a nivel físico como psíquico. Así, se enumeran algunas coincidencias entre ambos: cambios vitales, edad, sexo, "embarazo" de la palmera hembra, enfermedades y sus remedios, muerte... destacándose el tema de la añoranza que la palmera hembra siente por su compañera macho, por su deseo de que éste la fecunde con su polen, tema que también se encuentra en el tratado agrícola del andalusí Ibn Wāfid ${ }^{14}$.

La Agricultura Nabatea parece conceder igualmente un cierto carácter humano a la palmera cuando refiere que este árbol se denomina "hermana de Adán”, nombre con respecto al cual se rechazan orígenes falsos (por ejemplo, que la palmera apareció cuando nació Adán ${ }^{15}$, o que éste comía siempre de sus frutos), para explicar que tan sólo se debe a los múltiples beneficios que tiene esta especie -a nivel alimenticio y terapéutico básicamente-, beneficios diferentes pero casi iguales en cantidad a los atribuidos al personaje citado ${ }^{16}$. Por su parte, el sevillano Ibn al- ${ }^{\mathrm{C}} \mathrm{A} w w a \bar{m}$ no recoge, en su obra agrícola, el tema de la fecundación de la palmera en los términos que se han visto, pero sí reproduce lo dicho por varios hadices. De esta manera, acaba el capítulo dedicado al plantío de dicha palmácea indicando que el Profeta Muhammad rompía el ayuno con dátiles, que Dios dio este fruto a María, y que comer siete dátiles de la variedad ${ }^{c} a \hat{y} w a$ antes de acostarse mata los gusanos intestinales, tradiciones a las que añade que Set, hijo de Adán, fue el primer hombre que plantó palmeras ${ }^{17}$.

La vid (Farooqi 1989: 40-45; Mansūur 1994: 66-73) cuenta con once menciones en el Corán bajo el término ${ }^{c}$ inab y su plural $a^{c} n \bar{a} b$. En la mayor parte de ellas acompaña al árbol del que acabo de hablar, por lo que el contexto religioso en el que se encuentra es el mismo que el de la palmera, es decir, cultivo de lugares paradisíacos y de copioso fruto gracias a la generosidad divina:

"Por medio de esta agua os hemos creado palmerales y viñedos en los que encontráis frutos abundantes, de los que coméis" (XXIII, 19). "Tienen un signo en la tierra muerta, que hacemos revivir y de la que hacemos salir el grano que les alimenta. Hemos plantado en ella palmerales y viñedos, hemos hecho brotar de ella manantiales" (XXXVI, 33-34). "En cambio, a los temerosos de Dios se les deparará el éxito: vergeles y viñedos...” (LXXVIII, 31-32) ${ }^{18}$.

14 J.M. Carabaza, Ahmad b. Muhammad b. Haŷŷây al-Išbîlī: al-Muqnic fĩ l-filāha. Introducción, estudio y traducción, con glosario, Tesis Doctoral ed. en microfichas (Granada 1988) 230-231; Ibn Wahšiyya, al-Filāha alnabatiyya, ed. T. Fahd (Damasco 1995) II, 1358-1362.

${ }^{15}$ En contra de esto, en las obras de medicina traducidas por Cyril Elgood se afirma que la palmera fue creada de la misma tierra con la que se dio origen a Adán. C. Elgood, "Tibb-ul-Nabbi”, 96 y 189.

${ }^{16}$ Ibn Wahšiyya, al-Filāha al-nabatiyya, II, 1339-1341 y 1406-1422.

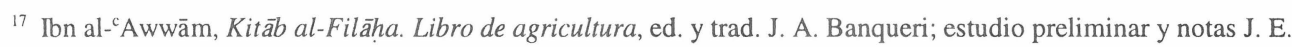
Hernández Bermejo y E. García Sánchez (Madrid 1988, ed. facsímil de 1802) I, 349.

18 Véase, igualmente, Corán II, 266; VI, 99; XII, 36; XIII, 4; XVI, 11 y 67; XVII, 91; XVIII, 32 y ss. y LXXX, 28. Alusión a emparrados en VI, 141. 
En los hadices, hay diversos temas en los que interviene la vid y las uvas y pasas que de ella se obtienen; así, se habla de cómo hay que vender tanto unas como otras, se insiste en que se ha de evitar unirlas a otros productos para la obtención de vino -sobre todo la mezcla de pasas y dátiles ${ }^{19}$-, se indican formas de consumo, etc.:

"El Profeta, Dios lo bendiga y salve, prohibió vender uvas hasta que éstas ennegrecieran y la venta de granos hasta que éstos estuvieran recios"; "El Profeta, Dios lo bendiga y salve, prohibió la muzābana [venta del producto aún en el árbol], que consiste en vender el fruto de la palmera en la misma medida que si fueran dátiles ya maduros, y la venta de pasas en la misma medida que si fueran uvas aún en la vid"20.

"Al Profeta, Dios lo bendiga y salve, se la echaban las pasas en el odre y él bebía de su jugo ese mismo día, la jornada siguiente y el día posterior y, cuando llegaba la tarde del tercer día, lo ingería y lo daba a beber pero, si sobraba algo, lo tiraba"21 .

Curiosamente, casi todas las colecciones de hadices recogen la prohibición de que se denomine la vid con el nombre karm dada la connotación religiosa de este vocablo. No obstante, la palabra karm será después frecuentemente utilizada en los tratados de agricultura árabes para este arbusto:

"El Profeta, Dios lo bendiga y salve, dijo ... que ninguno de vosotros llame a la vid alkarm, pues esta palabra denomina al hombre musulmán", o bien: "El Profeta, Dios lo bendiga y salve, dijo: hablan de al-karm, pero al-karm significa únicamente el corazón del creyente"22.

Esta misma prohibición se halla también en algunos tratados de medicina profética, en los que la vid aparece como un producto de iguales beneficios que la palmera, por lo que es denominada como ujt al-najla o hermana de esta palmácea ${ }^{23}$. En efecto, las uvas se consideran el mejor fruto y el más alimenticio, sobre todo cuando están bien maduras. Igualmente, recogen estas obras médicas que al Profeta le encantaba comer tanto uvas como melones y que Noé, al quejarse a Dios de su dolor, obtuvo la revelación de que debía comer uvas y que, al hacerlo, su dolor desapareció ${ }^{24}$.

19 Véase, a modo de ejemplo de la prohibición de dicha mezcla, al-Bujārī, Șaḩ̣̆ IV, 1797 número 5602.

${ }^{20}$ Cfr. Sunan de Abū Dāwud número 2927 en Mawsūc at al-ḥadīt al-šarîf, s.v. "“inab” y al-Bujārī, Saḥ̂h II, 642 número 2171.

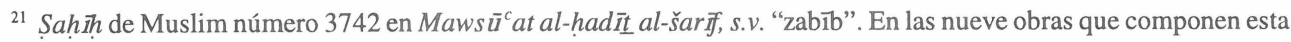
enciclopedia se citan más las pasas que las uvas, pues el término zabib posee ciento noventa y cuatro entradas en tanto que el vocablo ${ }^{c}$ inab registra setenta y tres.

22 Sahịh de Muslim número 4170 en Maws $\bar{u}^{c}$ at al-hadīt al-šarîf, s.v. "“inab"; al-Bujārī, Sahịh IV, 1946 número 6183. Igualmente en al-Nawawī, Riyād al-șālihīn, 450 números 1738 y 1739 y El jardín de los justos, 400 número 1746.

${ }^{23}$ M. al-Dahabī, al-Ṭibb al-nabawī, 78; C. Elgood, “Tibb-ul-Nabbi”, 105.

${ }^{24}$ M. al-Dahabī, al-Tíbb al-nabawī, 72; C. Elgood, "Tibb-ul-Nabbi”, 100 y 187-190. 
Al tiempo que se indican cuáles son las mejores especies de uvas y se especifican sus grados de humedad y sequedad correspondientes, se mencionan en los libros de la medicina del Profeta los siguientes efectos terapéuticos de dicho fruto: en forma de emplasto, combaten los tumores agudos; estimulan las relaciones sexuales; si se toman cincuenta uvas rojas y se cuecen en agua (hasta que ésta se reduzca a un tercio), y luego se ingiere el agua y las uvas, es un tratamiento eficaz contra los forúnculos; o bien, si se toman granos de uva verde agria y se administran al que padezca de pleuresía y tenga la lengua dilatada, le será muy beneficioso y recuperará pronto la salud ${ }^{25}$. Por otra parte, hay que evitar la ingestión de uvas verdes aún no maduras ya que producen hinchazón, flatulencia y sueltan el vientre y, si se comen en exceso, provocan sed. Para remediar estos males, se toma granada agria y, si se llega a vomitar, se ingieren granos de zumaque ${ }^{26}$.

Las pasas también intervienen en la medicina profética y en mayor medida que las uvas. De este modo, dado que las primeras son calientes y húmedas, provocan calor y sed, engordan los cuerpos de las personas de temperamento frío, y mezcladas con ojimiel son beneficiosas para las personas de temperamento caliente; sus pepitas irritan el estómago pero no son perjudiciales si se mezclan con cuescos de granada en polvo; cocidas con agua y miel, resulta una bebida dulce que combate cualquier dolor; cocidas con cártamo, facilitan la excreción; finalmente, sus beneficios son mayores que los de los dátiles y, de hecho, quien toma pasas, corazones de pistacho y romero cada día en ayunas, fortalece su inteligencia ${ }^{27}$.

Además de la prohibición de mezclar pasas con dátiles y de consumir jugo de pasas más allá del tercer día de haberlas preparado, obviamente porque en ambas circunstancias se obtenía una bebida fermentada que no debía ingerirse, en algunas obras consultadas se recogen otras tradiciones provenientes de diversos autores (Tamīm al-Dārī, Ibn ' Abbās, al-Zuhrī...) en las que interviene el Profeta Muhammad y su pariente 'Alī. Así, puede leerse que el Profeta, cuando se le ofrecieron unas pasas, las tomó en sus manos y dijo a sus amigos: "Tomad pues ¡qué mejor comida hay que las pasas! Hacen desaparecer la fatiga, apagan el enojo, fortalecen los nervios, perfuman el aliento, anulan la flema y depuran el color". Igualmente, se atribuye $a^{c}$ Ali el consejo de que se tomen todos los días veintiuna pasas rojas, puesto que así nada desagradable afectará al cuerpo del que las ingiera. A ello se suma el que han de consumirse las pasas sin pepitas o huesos pues en éstos sólo hay males, en tanto que el resto del fruto únicamente produce salud ${ }^{28}$.

En los tratados de agricultura árabes, donde el término karm es el más empleado para designar la vid como ya he dicho en tanto que ${ }^{c}$ inab queda restringido al fruto, se establecen

${ }_{25}$ M. al-Dahabī, al-Tỉbb al-nabawĩ, 71-72 y 78; C. Elgood, "Tibb-ul-Nabbi", 60, 100 y 105; Ibn Habīb, Mujtașar, 23/57; Islamic Medical Wisdom, 169.

${ }^{26}$ M. al-Dahabī, al-Tibb al-nabawī, 72; C. Elgood, “Tibb-ul-Nabbi”, 100.

${ }^{27}$ M. al-Dahabī, al-Tibb al-nabawī, 56-57; C. Elgood, "Tibb-ul-Nabbi”, 59 y 88; Islamic Medical Wisdom, 72.

${ }^{28}$ M. al-Dahabī, al-Tibb al-nabawī, 56-57; C. Elgood, “Tibb-ul-Nabbi”, 88; Islamic Medical Wisdom, 181. 
paso a paso las distintas labores y enclaves que se destinan a este producto a través de variados capítulos, pero no se observa en éstos nada que mantenga relación con las tradiciones proféticas que acabo de señalar, por lo que no aportan ningún dato más al tema que me ocupa. Solamente diré que la importancia de la vid se refleja en el número de páginas que cada una de las obras agrícolas dedica a su plantío y que excede, con mucho, al destinado al resto de los cultivos ${ }^{29}$.

El olivo (Farooqi 1989: 34-39; Manșūr 1994: 43-50) es el tercer árbol más citado en el Corán (bajo el término zaytūn), donde tan sólo en dos ocasiones aparece en solitario, figurando las cinco menciones restantes acompañado de otras especies vegetales como, por ejemplo, la palmera, el granado, la vid y la higuera. Además de registrarse en los mismos contextos positivos de las dos especies que ya se han tratado, el olivo es calificado de "árbol bendito" dadas sus propiedades alimenticias y el variado uso de su aceite:

“...Terrenos plantados de vides, olivos y granados, parecidos y diferentes. Cuando fructifican, ¡mirad el fruto que dan y cómo madura! Estos son signos para gente que cree" (VI, 99). "Gracias a esa agua, hace crecer para vosotros los cereales, los olivos, las palmeras, las vides y toda clase de frutos. Hay en ello, ciertamente, un signo para gente que reflexiona" (XVI, 11). "Dios es la Luz de los cielos y de la tierra. Su Luz es comparable a una hornacina en la que hay un pabilo encendido. El pabilo está en un recipiente de vidrio, que es como si fuera un astro fulgurante. Se enciende de un árbol bendito, un olivo, que no es del Oriente ni del Occidente, y cuyo aceite casi alumbra aun sin haber sido tocado por el fuego..." (XXIV, $35)^{30}$.

En el conjunto de las tradiciones proféticas vuelve a reiterarse la idea de que el olivo es un árbol bendito, por lo que el hadiz que se repite con más asiduidad (con algunas variantes) es el siguiente: "Dijo el Profeta, Dios lo bendiga y salve, comed aceite y ungíos con él, pues proviene de un árbol bendito" ${ }^{1}$. El olivo en sí apenas es objeto de comentarios, dándose la circunstancia de que la tradición más reiterada es la que muestra al Profeta Muhammad leyendo la azora XCV en la oración de la noche: "Escuché al Profeta, Dios lo bendiga y salve, leyendo en la oración nocturna "ipor las higueras y los olivos!”, y no he oído a nadie con mejor voz que la suya"32.

${ }^{29}$ Véase, a modo de ejemplo, Abū l-Jayr, Kitāb al-Filāha. Tratado de agricultura, ed. y trad. J. M. Carabaza Bravo (Madrid 1991) 272-289; J.M. Carabaza, Ahmad, 196-218 y 297-313; Ibn al-'Awwām, Kitāb al-Filāha I, 351-390; Ibn Wahš̌iyya, al-Filāha al-nabatìyy II, 915-1132.

30 Vide, asimismo, Corán VI, 141; XXIII, 20; LXXX, 29 y XCV, 1.

${ }^{31}$ Sunan de al-Tirmidī número 1774 en Maws $\bar{u}^{c}$ at al-hadīt al-šarîf, s.v. "zayt".

32 Sahịh de Muslim número 708 en Maws $\bar{u}^{c}$ at al-hadīt al-šarîf, s.v. "zaytūn". Este vocablo, como ya he indicado, no es citado apenas en los hadices y, de hecho, únicamente registra treinta y seis entradas en el grueso de la enciclopedia aludida. En contrapartida, el término zayt cuenta con un total de setenta citas. 
Además de otros temas, los variados usos del aceite son los que más destacan en el grueso de la tradición profética. Así, puede verse su empleo en la alimentación: “ “'̄'iša, esposa del Profeta -Dios lo bendiga y salve-, dijo una vez muerto éste: nunca se sació de pan y aceite dos veces en un mismo día"33; su uso como ungüento purificador: "El Profeta, Dios lo bendiga y salve, se ungía la cabeza con aceite y así quedaba en estado sacro, libre de falsedades"34, o bien algunas de sus acciones terapéuticas: "El Profeta, Dios lo bendiga y salve, prescribió contra la pleuresía cúrcuma, costo y aceite que se administran por vía oral”35.

Este último remedio, y otros más, están recogidos en las obras de medicina profética ya aludidas anteriormente. Sin especificaciones sobre sus diversos tipos sino en un sentido general, el aceite de oliva interviene en los siguientes tratamientos: machacado con ajenuz y costo amargo e instilado por la nariz, cura algunas afecciones de la garganta; cocido con sen, sirve de purgante contra el efecto de los venenos y es útil para la flema y el dolor de espalda; untándose con él, se fortalece el pelo y los miembros y se retrasa la aparición de las canas; bebido, es útil contra los venenos (por eso se le llama "la triaca de los pobres"), suelta el vientre, calma el dolor de éste y expulsa sus tenias; es beneficioso contra las hemorroides; masticando hojas de olivo, se remedia la estomatitis ulcerosa, el carbunco, las pústulas y la urticaria; cocido con ruda e instilado en el oído, calma las palpitaciones de éste; aplicado con sal en la pierna, tras haber hecho un fuerte masaje de la cadera a los pies, es útil contra la ciática; untando con aceite y sal los pies, antes de dormir, durante dos noches, se mejora la paraplejía; finalmente, inhalado con aceite de vacas trotonas al final del día, en el baño, sirve para combatir la lepra ${ }^{36}$.

Por otra parte, se puntualiza en algunas de estas mismas obras que el aceite onfacino, resultante del prensado de aceitunas verdes, es frío y seco y que no debilita el estómago (otros aceites distintos al de oliva sí lo hacen); que el aceite obtenido de uvas maduras es caliente con moderación y que tiende a ser húmedo, dándose la circunstancia de que, cuanto más añejo, más caliente se vuelve; que las aceitunas verdes son frías y secas, muy nutritivas, fortalecen el estómago, estimulan el apetito sexual y resultan útiles contra la intoxicación por inhalación de vapores nocivos; que las aceitunas negras son calientes y secas, generan atrabilis y son malas para el estómago, y que las aceitunas saladas son beneficiosas contra las quemaduras de fuego ${ }^{37}$.

33 Ídem número 5283, s.v. "zayt". El mismo uso de pan y aceite como alimento en al-Nawawī, Riyāẹ al-sāalihịn, 335 número 1265 y El jardín de los justos, 305 número 1272.

34 Sunan de Ibn Māŷah número 3074 en $M a w s \bar{u}{ }^{c}$ at al-ḥadīt al-šarĩf, s.v. "zayt".

35 Ídem número 3458.

${ }^{36}$ Cfr. M. al-Dahabī, al-Ṭibb al-nabawī, 58-59; C. Elgood, “Tibb-ul-Nabbi”, 89-90; Ibn Habīib, Mujtașar, 24/58 y 34/67; Islamic Medical Wisdom, 89, 94, 167 y 168.

${ }^{37}$ M. al-Dahabī, al-Tibb al-nabawī, 58-59; C. Elgood, “Tibb-ul-Nabbi”, 89-90. 
$\mathrm{Al}$ ser un ungüento purificador, no debe extrañar que el aceite de oliva se use para repeler a Satanás y así, según cuenta la tradición, ungirse con él libra a la persona durante cuarenta días de que se le acerque el diablo, pues éste no puede nada contra él ${ }^{38}$. Incluso, tres hojas de olivo intervienen en la elaboración de un amuleto que libra a su dueño de todo mal que afecte a sus dientes ${ }^{39}$.

La idea reiterada desde el Corán de que el olivo es un árbol bendito es la que también se presenta en algunas obras de agricultura árabes, concretamente en la Agricultura Nabatea y en el Libro de agricultura de Ibn al-'Awwām, recopilador por excelencia que dice transmitir, a este respecto, la opinión del agrónomo sevillano Abū l-Jayr y otros autores de geoponimia ${ }^{40}$. Dada esta circunstancia, es lógico que Ibn al- ${ }^{\mathrm{C}} \mathrm{A} w w a \bar{m}$ aconseje que lo cuiden únicamente personas honestas, y que no se acerque a él quien no se halle en estado puro, si se quiere obtener un buen rendimiento: "También se dice que cometiendo el encargo de este cultivo y régimen del olivo á varon honesto, puro, libre de deshonestidades y costumbres corrompidas, cargará por esto de mucho y abundante fruto; y que si el dueño estuviere alegre y contento con el que Dios le diese, por esto mismo le colmará de todo género de bienes, y le será propicio. Que no se acerque á este arbol, particularmente al plantarlo, muger menstruada, ni varon con impureza legal. Soltero ni adúltero [ó impio], respecto á que cargaría de poca y pequeña aceytuna (salva la voluntad de Dios); ni que al aceyte ya defecado se acerque sino solo persona casta" $^{\prime \prime}$.

A modo de conclusión, tan sólo apuntar que es lógica la mayor presencia de las tres especies analizadas en el libro sagrado islámico (recordemos su aparición en la Biblia, por ejemplo), puesto que se trata de cultivos conocidos desde muy antiguo -ya los babilonios, asirios y egipcios se aprovechaban ampliamente de ellos-, y profundamente arraigados tanto en culturas anteriores al Islam como en el paisaje en el que se enmarca la revelación coránica. Sin duda, si hay algún árbol que se identifica con la civilización arabo-islámica es la palmera, al igual que los dos cultivos típicamente mediterráneos son, hasta hoy en día, el olivo y la vid. Sus beneficios, no sólo reducidos a los frutos sino también a los productos derivados de éstos y a otras partes de su morfología (hojas, tronco, ramas...), no podían pasar inadvertidos en las obras de carácter religioso, en donde se habla al hombre con el lenguaje de las cosas que le rodean y le son útiles. Del mismo modo, dada su repercusión en la vida diaria, estos cultivos conservan hasta la actualidad su propia simbología heredada de las culturas por las que han ido dejando huella.

\footnotetext{
${ }^{38}$ M. al-Dahabī, al-Ṭibb al-nabawī, 58; C. Elgood, “Tibb-ul-Nabbi”, 89; Ibn Habīb, Mujtașar, 42-43/75.

39 Islamic Medical Wisdom, 17.

${ }^{40}$ Ibn al- ${ }^{c}$ Awwām, Kitāb al-Filāha I, 240; Ibn Waḥšiyya, al-Filāha al-nabațiyya, ed. T. Fahd (Damasco 1993) I, $52-$ 53.

${ }^{41}$ Ibn al- ${ }^{\mathrm{C}} \mathrm{Aww}$ ām, Kitāb al-Filāha I, 243.
} 
